\title{
Multi-satellite study of the excitation of Pc3 and Pc4-5 ULF waves and their penetration across the plasmapause during the 2003 Halloween superstorm
}

\author{
G. Balasis ${ }^{1}$, I. A. Daglis ${ }^{2}$, I. R. Mann ${ }^{3}$, C. Papadimitriou ${ }^{1,2}$, E. Zesta ${ }^{4}$, M. Georgiou ${ }^{2}$, R. Haagmans ${ }^{5}$, and \\ K. Tsinganos ${ }^{2}$ \\ ${ }^{1}$ Institute for Astronomy, Astrophysics, Space Applications and Remote Sensing, \\ National Observatory of Athens, Athens, Greece \\ ${ }^{2}$ Section of Astrophysics, Astronomy and Mechanics, Department of Physics, University of Athens, Athens, Greece \\ ${ }^{3}$ Department of Physics, University of Alberta, Edmonton, Alberta, Canada \\ ${ }^{4}$ Geospace Physics Laboratory, Heliophysics Science Division, NASA Goddard Space Flight Center, \\ Greenbelt, MD 20771, USA \\ ${ }^{5}$ European Space Research and Technology Centre, European Space Agency, Noordwijk, the Netherlands
}

Correspondence to: G. Balasis (gbalasis@noa.gr)

Received: 8 June 2015 - Revised: 9 September 2015 - Accepted: 9 September 2015 - Published: 5 October 2015

\begin{abstract}
We use multi-satellite and ground-based magnetic data to investigate the concurrent characteristics of Pc3 (22$100 \mathrm{mHz}$ ) and Pc4-5 (1-22 $\mathrm{mHz})$ ultra-low-frequency (ULF) waves on the 31 October 2003 during the Halloween magnetic superstorm. ULF waves are seen in the Earth's magnetosphere, topside ionosphere, and Earth's surface, enabling an examination of their propagation characteristics. We employ a time-frequency analysis technique and examine data from when the Cluster and CHAMP spacecraft were in good local time (LT) conjunction near the dayside noon-midnight meridian. We find clear evidence of the excitation of both Pc3 and Pc4-5 waves, but more significantly we find a clear separation in the L shell of occurrence of the Pc4-5 and Pc3 waves in the equatorial inner magnetosphere, separated by the density gradients at the plasmapause boundary layer. A key finding of the wavelet spectral analysis of data collected from the Geotail, Cluster, and CHAMP spacecraft and the CARISMA and GIMA magnetometer networks was a remarkably clear transition of the waves' frequency into dominance in a higher-frequency regime within the Pc3 range. Analysis of the local field line resonance frequency suggests that the separation of the Pc4-5 and Pc3 emissions across the plasmapause is consistent with the structure of the inhomogeneous field line resonance Alfvén continuum. The Pc4-5 waves are consistent with direct excitation by the solar wind
\end{abstract}

in the plasma trough, as well as Pc3 wave absorption in the plasmasphere following excitation by upstream waves originating at the bow shock in the local noon sector. However, despite good solar wind coverage, our study was not able to unambiguously identify a clear explanation for the sharp universal time (UT) onset of the discrete frequency and largeamplitude Pc3 wave power.

Keywords. Ionosphere (wave propagation) - magnetospheric physics (magnetospheric configuration and dynamics; storms and substorms)

\section{Introduction}

Ultra-low-frequency (ULF) plasma waves are large-scale phenomena whose wavelength can be comparable to the size of the Earth's magnetosphere. A combination of concurrent observations at many locations in different regions of geospace is needed to understand in depth the generation and propagation of ULF waves (see e.g. Takahashi and Anderson, 1992; Liu et al., 2010; Menk, 2011, and references therein). ULF waves significantly influence magnetospheric processes - in particular ring current and radiation belt dynamics (e.g. Baker and Daglis, 2007) - due to their potential for strong interactions with charged particle populations. As a result the 
nature of the propagation of ULF waves to low L shells has taken on a new significance.

In the past decade, a critical mass of high-quality observation data of electric and magnetic fields in the Earth's magnetosphere has been progressively accumulated, especially with multi-satellite missions like ESA's Cluster and NASA's THEMIS spacecraft and more recently with NASA's Van Allen Probes. New analysis tools have effectively enhanced the scientific exploitation of the continuously accumulated data. In particular, recent advances in time-frequency analysis techniques using wavelet transforms have the potential to lead to versatile tools that offer insight into both spatial and temporal properties of ULF waves (Balasis et al., 2012, 2013). Understanding the wave characteristics at different points both in space and time can in turn shed light on the way that these waves can impact magnetospheric dynamics and, therefore, trigger space weather effects.

Recent magnetic field missions flying in a low Earth orbit (LEO), like Ørsted, CHAMP and ST-5, have enabled us to study, in situ, ULF wave occurrence in the topside ionosphere (Jadhav et al., 2001; Sutcliffe and Lühr, 2003; Engebretson et al., 2008). Pc3 ULF waves with the period in the range 10-45 s (Jacobs et al., 1964) show up very clearly in the compressional component of the satellite magnetic field data, whereas on the ground, for shear/toroidal oscillations, their signature is found in the north-south component (Vellante et al., 2004). However, if compressional oscillations are coupled with the ionosphere they appear in all components of the geomagnetic field (Pilipenko et al., 2011). In particular, CHAMP, with its accurate magnetometer measurements for more than a decade (July-September 2010), has been one of the most successful satellite missions for the study of the Earth's magnetic field, offering, among other things, the possibility to initiate statistical studies on the occurrence of Pc3 upstream wave events in the topside ionosphere (Balasis et al., 2005; Heilig et al., 2007). Moreover, the ESA's recently launched (22 November 2013) multi-satellite Swarm mission is expected to advance our current understanding of ULF wave occurrence in the topside ionosphere.

The Halloween 2003 magnetic storm (29-31 October 2003) was a rare extreme event which provided an ideal set of conditions to investigate magnetospheric and ionospheric responses to strong and continuous solar wind driving by means of both ground-based and space observations (Horne et al., 2005; Loto' aniu et al., 2006; and, more recently, Sarris, 2014). It was characterised by a double peak (the first minimum of the $D_{\text {st }}$ index reached $-353 \mathrm{nT}$ on 30 October 2003, while the second minimum reached $-383 \mathrm{nT}$ on 31 October 2003), and it was associated with two X-class solar flares and coronal mass ejections (CMEs) that occurred in quick succession on 28 and 29 October 2003, respectively.

In this paper, we provide evidence for a rare simultaneous detection of a Pc3 ULF wave event by distinct satellite missions flying in the Earth's magnetosphere and topside ionosphere as well as by ground magnetic networks, showing how multipoint measurements can yield insight into ULF propagation. The Cluster and CHAMP satellites were in good local time (LT) conjunction in the time interval from 19:00 to 23:30 UT, near the dayside noon-midnight meridian, on 31 October 2003, during the recovery phase of the Halloween 2003 superstorm.

Geotail was exposed to the interplanetary magnetic field (IMF), being located outside the bow shock at the dawn flank during the same time period. The wavelet analysis of magnetic field data from these satellites combined with measurements from the closest stations to the magnetic footprint of the Cluster satellites on the ground (i.e. the Fort Yukon magnetometer station of the GIMA network in Alaska and Dawson City station of the CARISMA array in Canada) allowed us to make useful comparisons between the observations in the various data sets and draw inferences about the evolution and propagation of the ULF waves.

\section{Data processing and analysis}

The temporal resolution for our data sets is $1 \mathrm{~s}$ for CHAMP and GIMA data, $3 \mathrm{~s}$ for Geotail measurements, $4 \mathrm{~s}$ for Cluster measurements and $5 \mathrm{~s}$ for CARISMA data. During the Halloween superstorm, the Cluster spacecraft were flying in close configuration, and no significant differences are seen in the ULF wave observations among the four different spacecraft. Therefore, we only present observations from the Cluster-1 spacecraft with the understanding that very similar conditions were encountered by the remaining three Cluster spacecraft.

Magnetic field time series from the Geotail and Cluster spacecraft were transformed to a mean field-aligned (MFA) coordinate system in order to separate ULF field variations perpendicular to as well as along the magnetic field direction. The parallel component in the coordinate system is obtained from a 20 min running average of the measured magnetic field, which defines the background magnetic field. For dipolar-like field lines, such as at Cluster, the azimuthal component is positive eastward, and the meridional component points radially outward at the magnetic equator. ULF wave oscillations in these directions are referred to as compressional, toroidal and poloidal, respectively. For CHAMP measurements we looked at oscillations in the total magnetic field. This is considered a fairly good approximation of the magnetic field's compressional component when studying ULF waves in situ at the topside ionosphere (e.g. Balasis et al., 2005, 2012; Heilig et al., 2007).

ULF waves have been traditionally identified manually by examining a series of spectrograms based on the fast Fourier transform (FFT). Moreover, motivated by the continuously increasing amount of data collected by space missions and ground-based instruments, algorithms have been developed based on FFT spectra to automatically examine spectrograms and identify ULF waves. Therefore, a variety of simple FFT 

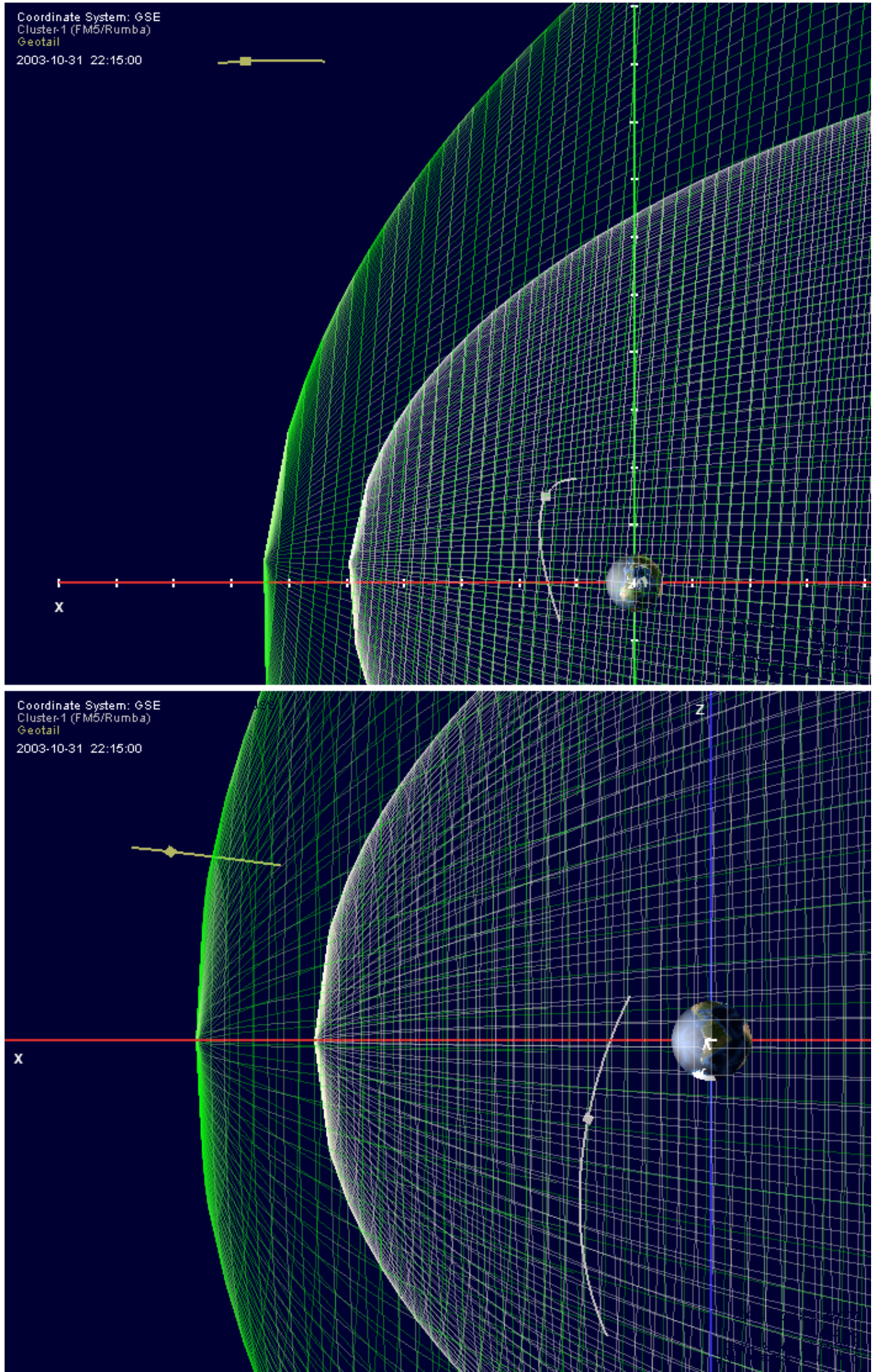

Figure 1. Cluster-Geotail position in the magnetosphere. Cluster-1 (grey) and Geotail (yellow) are shown in the $x-y$ (top) and $x-z$ (bottom) GSE planes from 19:00 to 23:30 UT on 31 October 2003. The square points indicate the satellites' position at 22:15 UT. 
automated routines exist (e.g. Anderson et al., 1992; Bortnik et al., 2007).

The performance of FFTs to identify ULF waves has been compared with wavelet transform techniques (Boudouridis and Zesta, 2007; Murphy et al., 2009), maximum entropy spectrum analysis (Ndiitwani and Sutcliffe, 2009), WignerVille distribution (Chi and Russell, 2008), and HilbertHuang transform (Kataoka et al., 2009). FFT seems to outperform the continuous wavelet transform in automated detection approaches, but the Morlet wavelet is better where the signal changes rapidly (Menk, 2011). Chi and Russell (2007) proposed the selection in the Wigner-Ville distribution to be based on the comparison with background noise for any assigned confidence interval. The Wigner-Ville distribution offers several advantages (especially for time-varying signals such as Pi2, Pc1 packets and phase skips in Pc3-4), including the ability to determine wave polarisation properties. However, the Wigner-Ville distribution approach is more computationally intensive than the FFT or wavelet approaches. The Hilbert-Huang transform decomposes the waveform into a small number of intrinsic mode functions for which the instantaneous frequency is determined by means of the Hilbert transform. The method is particularly well suited for irregular signals such as Pi1, Pi2 and storm-time Pc3 packets.

For studying the waves in the time-frequency domain we applied a continuous wavelet transform with the Morlet wavelet as the basis function to the complete time series. The methodology used for the spectral analysis is the same as that described by Balasis et al. (2013). Due to the fast motion through field lines in a LEO orbit, we are able to reliably detect Pc3 waves in CHAMP magnetic field measurements, but not Pc4-5 waves. Therefore, wavelet power spectra were separated into two categories according to their frequency bands: the first frequency range $(8-128 \mathrm{mHz})$ includes Pc3 waves, and the second frequency range $(1-32 \mathrm{mHz})$ includes Pc4-5 waves. Prior to the wavelet analysis the magnetic field data were high-pass-filtered. In the Pc3 frequency range, it was found empirically that a cut-off frequency of $16 \mathrm{mHz}$ for the high-pass-filter results in a reduction in the amplitude of pulsations with frequencies lower than or equal to $10 \mathrm{mHz}$ of approximately $90 \%$. Such a cut-off ensured that all low varying background activity, as well as possible contribution of Pc5 ULF waves, is eliminated. The selection of the cut-off frequency for the Pc5 case (i.e. $2 \mathrm{mHz}$ ) was based on similar criteria. In the case of ground stations, the filtered series have been normalised with their corresponding standard deviation values, before the wavelet analysis had been performed. This results in wavelet spectra with a unified power scale.

\section{Observations during the Cluster-CHAMP conjunction (19:00-23:30 UT, 31 October 2003)}

Figure 1 shows Cluster-1 (grey) and Geotail (yellow) in the $x-y$ (top) and $x-z$ (bottom) axes of the geocentric solar eclip- tic (GSE) coordinate system, with a model magnetopause based on the Sibeck model (Sibeck et al., 1991) and bow shock based on the Fairfield model (Fairfield, 1971). A solar wind pressure equal to $4 \mathrm{nPa}$ was used, according to the OMNI data for 22:15 on 31 October 2003. Orbits are shown from 19:00 to 23:30 UT, while the points indicate the satellites' position at 22:15 UT. Cluster is on an upwards pass and Geotail is on an outbound trajectory (plot produced using NASA's 4-D Orbit Viewer tool: http://sscweb.gsfc.nasa.gov/ tipsod/).

Figure 2 presents filtered time series (left panels) and wavelet dynamic spectra (right panels) for the Cluster magnetic field perturbations in the Pc3 and Pc5 frequency bands from 19:30 to 23:30 UT on 31 October 2003, i.e. when the Cluster-CHAMP conjunction occurred. During this time Cluster-1 moved from geocentric solar magnetic (GSM) coordinates $(2.8,-0.76,-6.8) R_{\mathrm{E}}$ to $(2.0,-3.4,1.7) R_{\mathrm{E}}$ from 19:30 to 23:30 UT in the dayside pre-noon sector. The top/bottom three panels of each column show the time series and wavelet spectra of the poloidal, toroidal, and compressional components of the Pc $3 / \mathrm{Pc} 5$ waves, respectively. The Pc5 wave observations seen by Cluster on the dayside near local noon, starting at 11:24 MLT in Fig. 2 can likely be attributed to solar wind perturbations compressing the Earth's magnetosphere, for example via the pressure pulse excitation mechanism discussed by Southwood and Kivelson (1990) and Sarris et al. (2010). The Pc3 wave power in Fig. 2 occurs in bursts at $\sim 19: 00, \sim 21: 10$, and $\sim 22: 20$ UT and is primarily in the toroidal and poloidal components. The Pc5 wave power appears in two distinct blocks in the toroidal and poloidal components but is weaker and continuous in the compressional component. The poloidal and parallel Pc5 wave components are both the result of fast-mode, compressional waves. The most interesting feature occurs at $\sim$ 22:20 UT, when the Pc3 wave power suddenly shifts to a much higher frequency range, from $\sim 20$ to $\sim 50 \mathrm{mHz}$, while at the same time the Pc5 toroidal power is terminated. We will show later that at that moment the satellite is crossing through the plasmapause boundary layer and is entering the plasmasphere, and that these wave characteristics can be explained as a result of the structure of the field line resonance Alfvén continuum. (We note that the term "plasmapause" is used here to refer to a region where the density changes from low values in the plasma trough to higher values inside the plasmasphere; we interpret waves as being excited at the local field line resonance frequency across this region.)

Figure 3 shows corresponding plots to Fig. 2 for Geotail. During the time interval under study Geotail was outside the bow shock at the dawn flank at the GSM location (11.3, $-16.9,7.9) R_{\mathrm{E}}$ at $19: 36 \mathrm{UT}$ and moved to $(14.5,-17.1,7.4)$ $R_{\mathrm{E}}$ at 23:24 UT. We examine Geotail data to look for evidence of the disturbances in its location which might have been driven by upstream waves as a result of ion specular reflection at the bow shock (e.g. Greenstadt and Olson, 1976) and which could have excited waves at Cluster and 


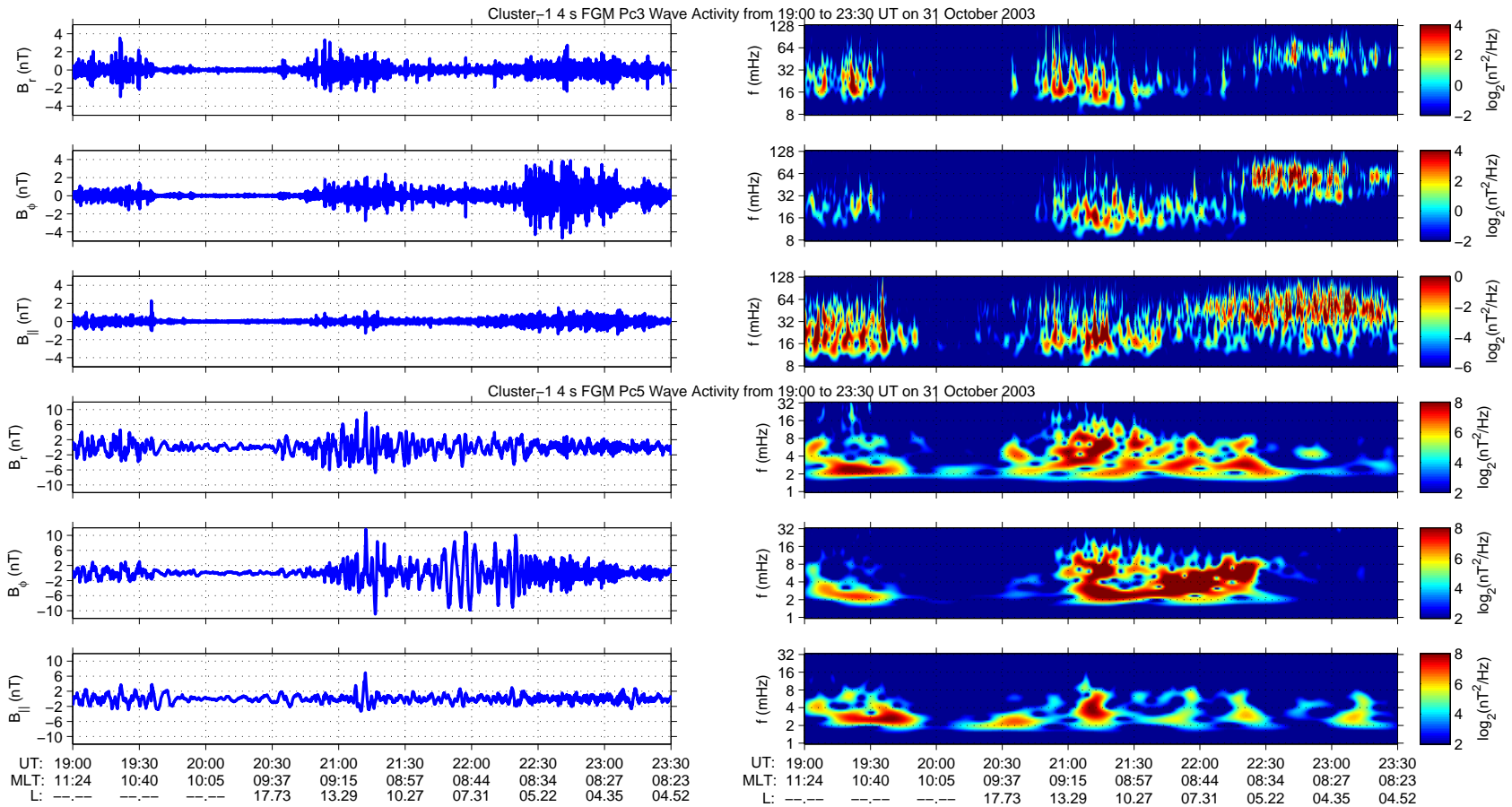

Figure 2. Cluster-1 wave observations between 19:00 and 23:30 UT on 31 October 2003. Left column: panels from top to bottom show the filtered time series of the poloidal, toroidal and compressional components, respectively, of the magnetic field, in the Pc3 range (three upper panels) and Pc5 range (three lower panels). Right column: panels from top to bottom show the corresponding wavelet power spectra. The corresponding MLT and $L$ values are also provided at the bottom of the graph.

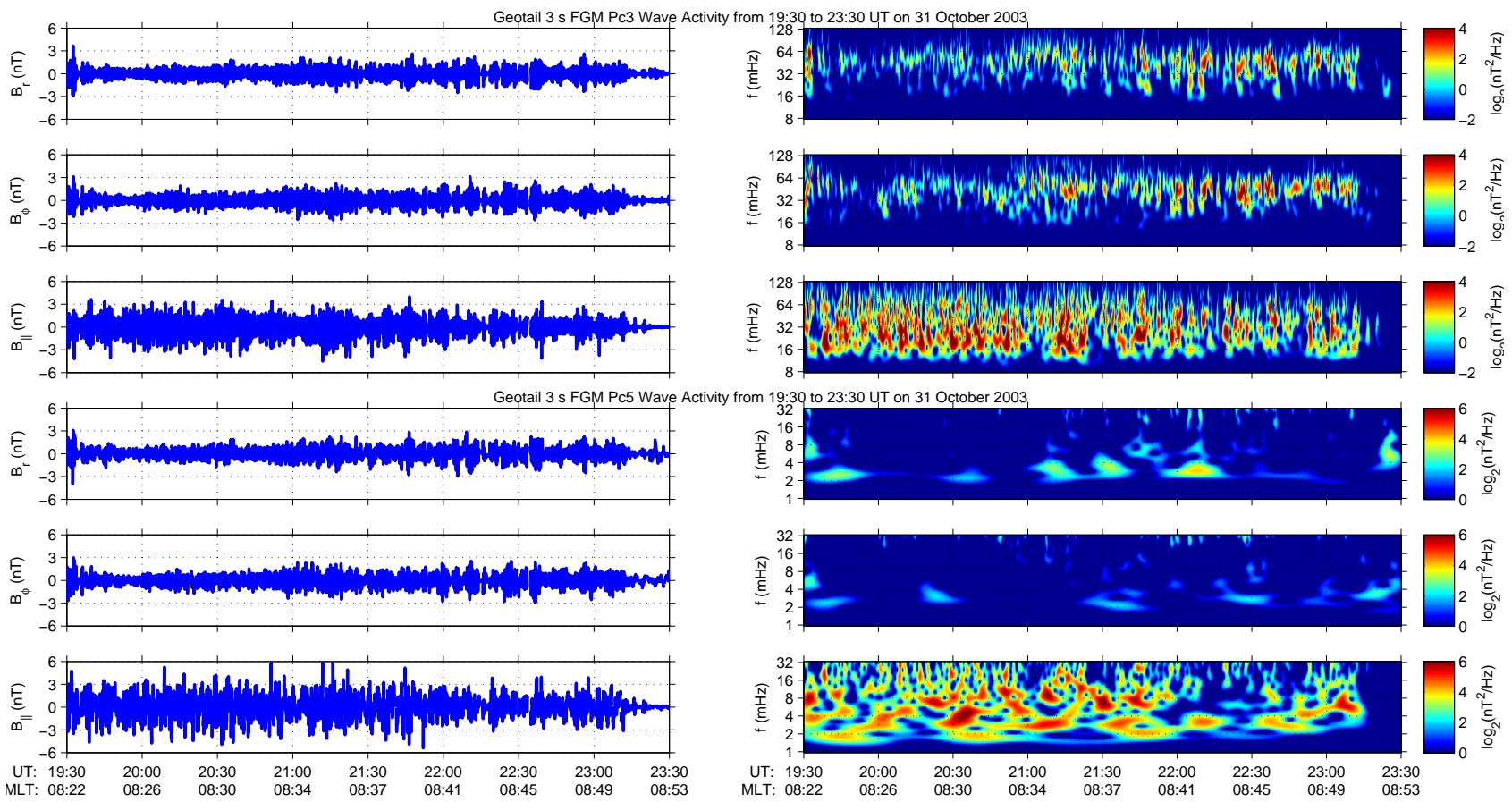

Figure 3. As in Fig. 2 but for the Geotail satellite. 

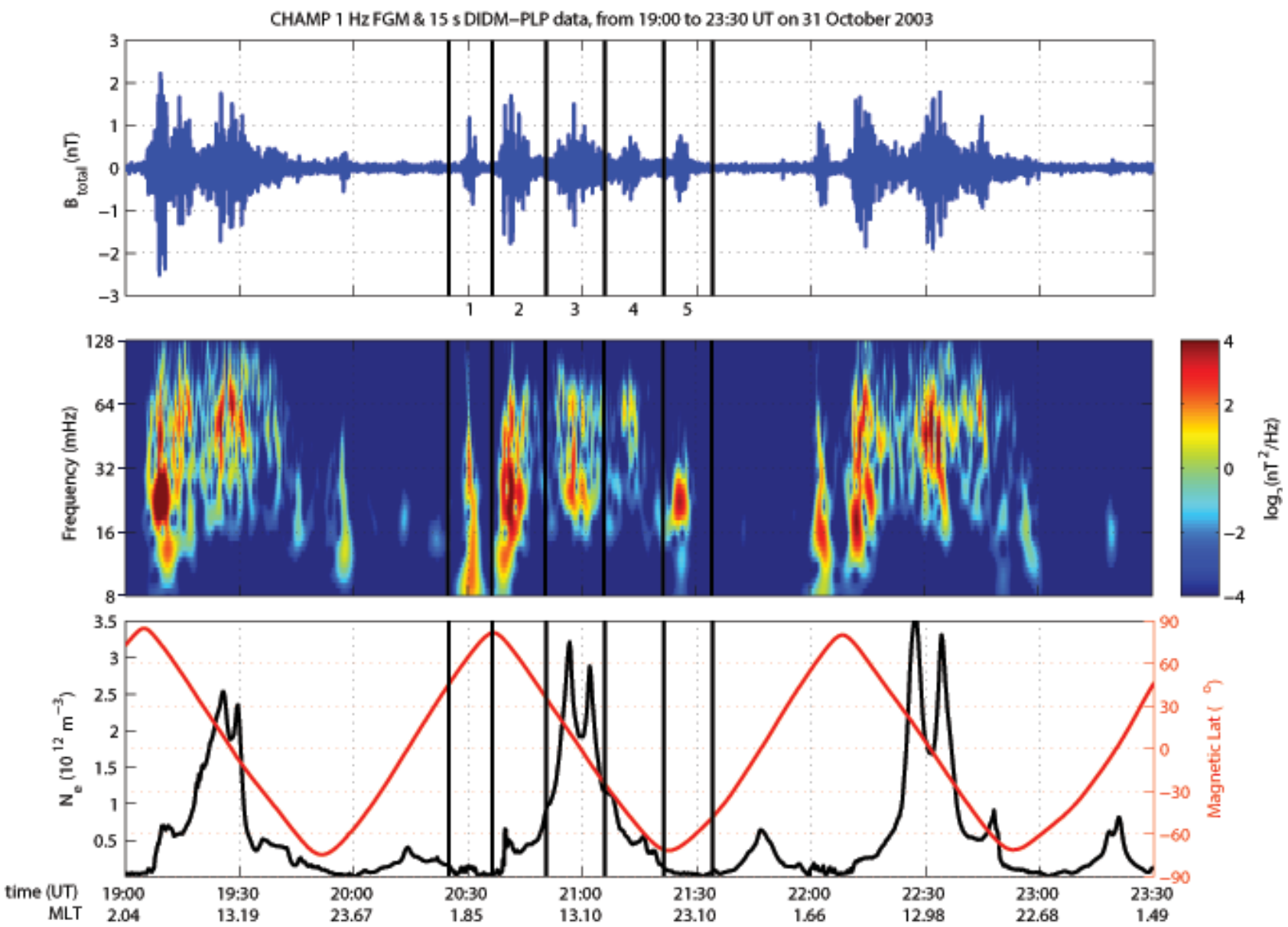

Figure 4. CHAMP ULF wave observations for the same time interval as in Figs. 2 and 3. Panels from top to bottom show the filtered time series of the total magnetic field, its corresponding wavelet power spectrum in the Pc3 range as well as the temporal variation in the electron density data along with its magnetic latitude dependence. The corresponding MLT values are also given at the bottom of the graph. The vertical lines in the middle orbit denote the time intervals corresponding to the key ionospheric areas discussed in the text.

CHAMP (see Fig. 4). Geotail sees strong persistent perturbations starting at approximately 19:00 UT and lasting until around 23:00 UT in the Pc3 and Pc5 compressional components covering almost their whole frequency range (16-64 and $2-32 \mathrm{mHz}$, respectively). However, for the Pc3 poloidal and toroidal components they cover a frequency range between 16 and $64 \mathrm{mHz}$ before 19:30 UT, while afterwards Pc3 observations are made between 32 and $64 \mathrm{mHz}$ only. In the time interval between 19:30 and 21:00 UT, Pc3 poloidal and toroidal disturbances are rather weak and they seem to intensify after that time. Interestingly, high-frequency (i.e. above $5 \mathrm{mHz}$ ) Pc5 poloidal and toroidal observations are also absent after 19:30 until 21:00 UT.

Figure 4 presents the CHAMP total magnetic field filtered time series and Pc3 wave dynamic spectra for the same time interval as in Figs. 2 and 3 for Cluster and Geotail, respectively. The third panel in Fig. 4 shows the electron density data derived from the $15 \mathrm{~s}$ planar Langmuir probe (PLP) measurements. The corresponding values of the CHAMP mag- netic latitude and magnetic local time (MLT) are also provided in that panel. The inclusion of the electron density recordings helps to identify the time segments of the signal that contain signatures of the post-sunset equatorial spread $\mathrm{F}$ (ESF) events (Stolle et al., 2005) and discriminate between Pc3 wave and plasma depletion occurrence. During the times of interest, the CHAMP satellite was approximately on a noon-midnight orbit with the ascending node on the nightside and descending on the dayside ( 13:00-01:00 MLT sector meridian).

The signatures of the key ionospheric areas crossed during one CHAMP orbit are identified in the Pc3 dynamic spectra of Fig. 4 (see the five time intervals during a single orbit which are marked with vertical lines). It is worth noting that magnetic disturbances in the Pc3 frequency band are observed over the auroral zones (intervals 1 and 2 correspond to the northern auroral zone, while intervals 4 and 5 to the southern auroral zone) and the dayside equator (interval 3), while wave power decreases significantly at mid-latitudes - 


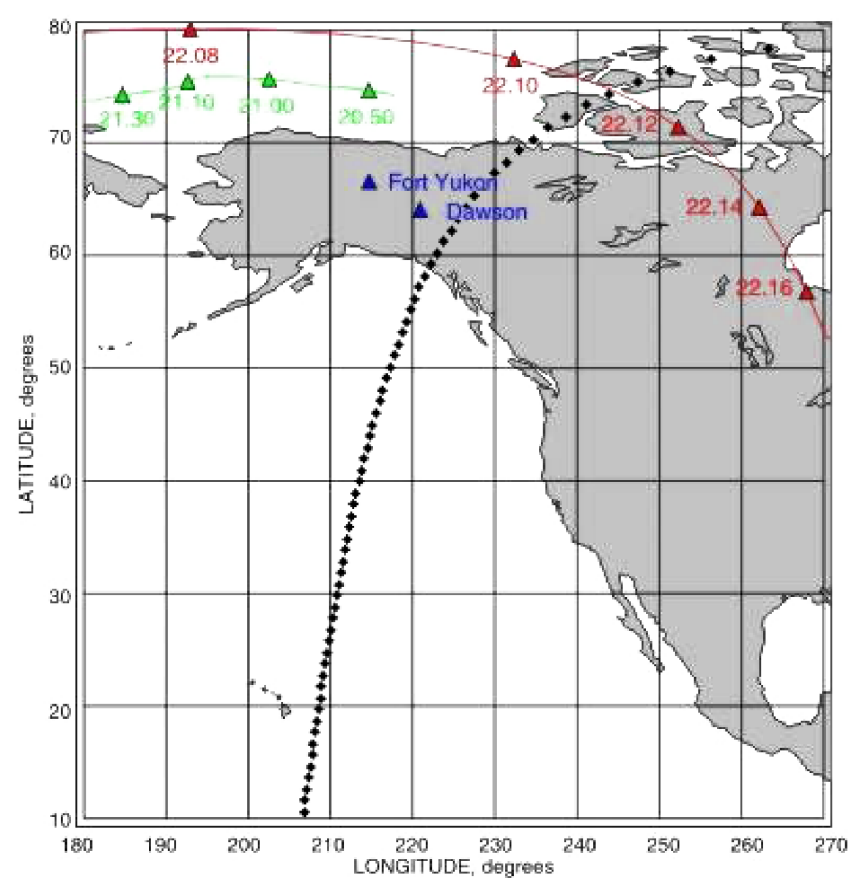

Figure 5. Map of the Cluster (red) and CHAMP (green) magnetic footprints on the 31 October 2003. The dashed line shows the meridian of local noon at 22:15 UT.

a profile that we attribute to strong ionospheric Hall and Pedersen currents there. Furthermore, a dramatic north-to-south asymmetry in the power in the Pc 3 band is observed over the auroral zones (the wave amplitude ratio is nearly a factor of 2 , while the wavelet power ratio is about 8 times larger), with the activity being more pronounced over the northern auroral oval. A nightside/dayside auroral oval asymmetry in the Pc3 power is also evident, with most of the power occurring on the dayside auroral oval (see intervals 2 and 4 corresponding to the dayside auroral oval in the Northern and Southern Hemisphere versus intervals 1 and 5 corresponding to the nightside auroral oval). On the other hand, because the equatorial electrojet disappears in the nightside, Pc3 power has significantly decreased over the nightside equator. Pc3 activity that is sporadically observed in the nightside is likely due to phenomena like currents enhanced during substorms or the propagation of Pi2 waves (frequency range $2-25 \mathrm{mHz}$ ) from the magnetotail. We note that from low Earth orbit platforms it can be difficult to differentiate between structured fieldaligned current systems and Pc3 waves even with a wavelet analysis.

The asymmetry between the Northern (winter) and Southern (summer) Hemisphere revealed by CHAMP observations in the power distribution of Pc3 power is consistent with the presence of stronger field-aligned currents (FACs) on the dayside in the Northern Hemisphere. During the time interval between 19:00 and 23:30 UT on 31 October 2003, the FAC density is larger in the Northern Hemisphere, both in the dayside and the nightside. Furthermore, due to the enhanced geomagnetic activity and a southward IMF $B_{z}$, the auroral ovals have expanded towards the magnetic equator and the lowest latitude where FACs are observed on the dayside reaching down to $67^{\circ}$ (Wang et al., 2006).

In order to examine the nature of the Pc3 power observed by CHAMP, and to seek periods of Pc3 ULF wave activity in this data set, we identified ground stations with locations corresponding to the magnetic footprint of Cluster- 1 between 19:00 and 23:30 UT on 31 October 2003 (Fig. 5; the dashed line shows the meridian of local noon at 22:15 UT). The Cluster-1 footprint at 21:00 UT on 31 October 2003 had a geomagnetic latitude and longitude of 75.64 and $202.54^{\circ}$, respectively. The magnetometer station of the GIMA network closest to the Cluster-1 footprint was Fort Yukon, while for the CARISMA array it was Dawson City. Two hours later, at 23:00 UT, Cluster-1 was still on the dayside, but its footprint was far from the two ground stations, at a geomagnetic latitude and longitude of 65.60 and $143.03^{\circ}$, respectively. Figures 6 and 7 present ground Pc 3 and Pc5 wavelet power spectra for the same time interval as in Fig. 2-4. In Fig. 6 and 7, time series of the $H, D$ and $Z$ geomagnetic field components along with their corresponding wavelet power spectra are shown for the Fort Yukon and Dawson City stations, respectively.

Figure 8 presents a composite of dynamic wavelet power spectra, covering the Pc3 wave activity as seen by the Geotail, Cluster-1 and CHAMP satellites as well as at the Fort Yukon and Dawson ground stations between 21:00 and 23:30 UT on 31 October 2003. In particular, Fig. 8 shows the wavelet power spectra of the toroidal component at Geotail outside the bow shock, toroidal and compressional components for Cluster-1 in the dayside magnetosphere, total field for CHAMP and $D$ components for Fort Yukon and Dawson, respectively. A remarkable feature of this wave event is the change of Pc3 frequency toward higher values between 22:23 UT (Cluster) and 22:30 UT (Dawson), recorded by Cluster, CHAMP and the ground stations at Fort Yukon and Dawson. The transition into a different frequency regime within the Pc3 range, from frequencies between 16 and $32 \mathrm{mHz}$ into frequencies centred between 55 and $60 \mathrm{mHz}$, was concurrently detected in the magnetosphere and topside ionosphere and on the ground. The high-frequency Pc3 waves present outside the bow shock at the dawn flank (Geotail) during this whole time period also seem to intensify somewhat at $\sim 22: 00$ UT. Shortly after, this same frequency is intensified in the Cluster compressional component, and a similar feature is also seen in the data from the two ground stations (this is also seen further east across the CARISMA array, but at lower amplitude further from local noon (not shown)). The same band abruptly initiates in the Cluster toroidal component at $\sim 22: 23$ UT. The high-frequency Pc3 band is also more intense through all latitudes in the CHAMP orbit through the dayside. 

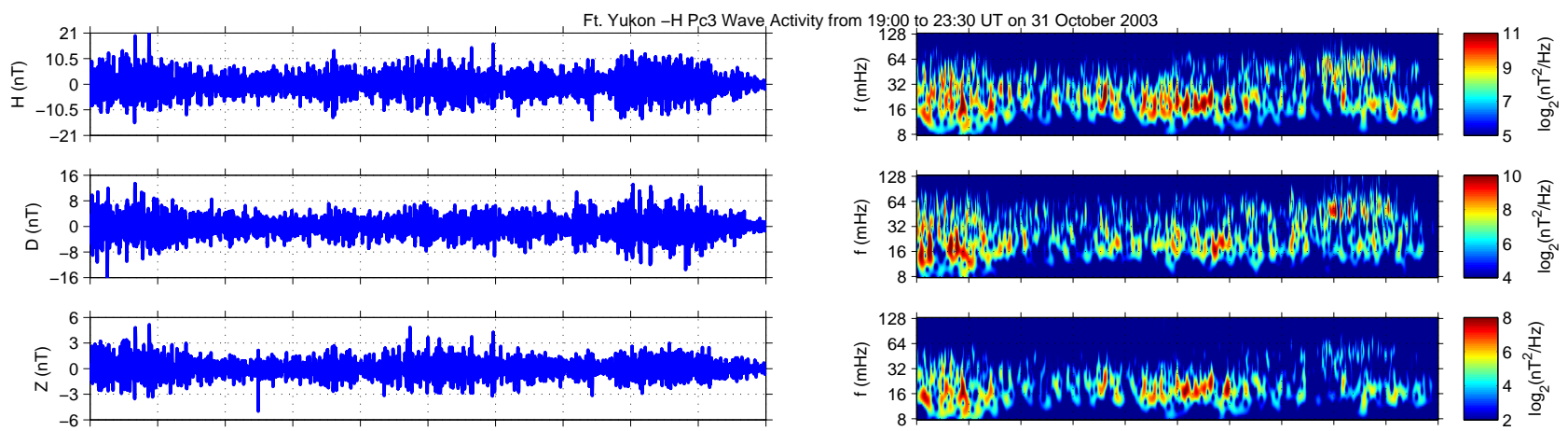

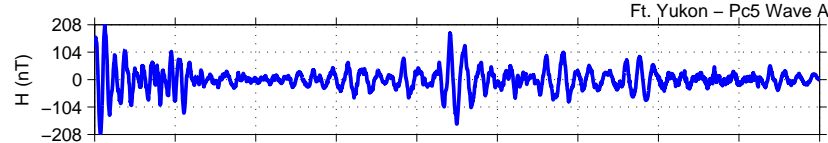

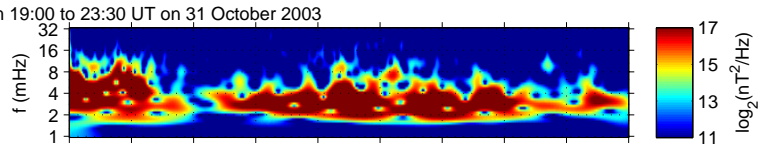

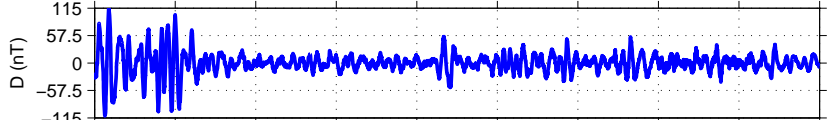
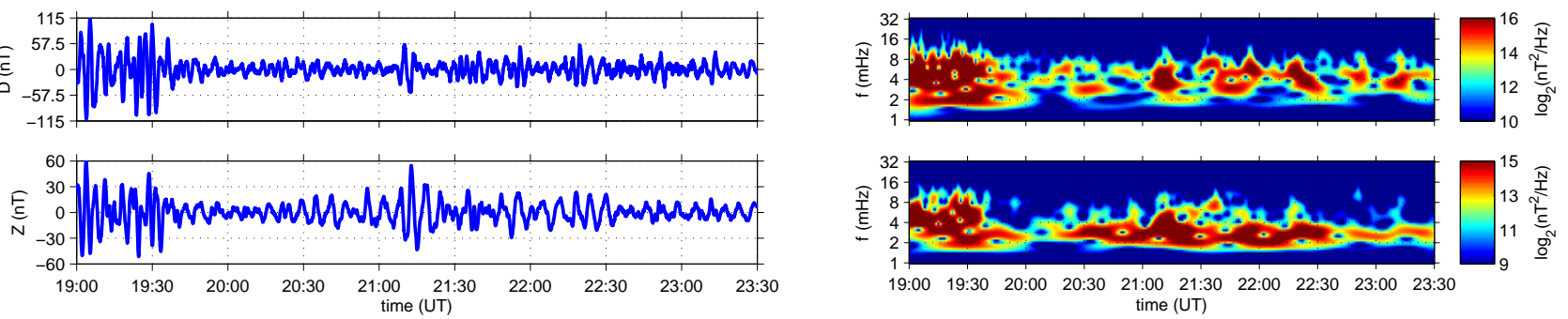

Figure 6. Fort Yukon ULF wave observations for the conjunction between Cluster and CHAMP. Left column: panels from top to bottom show the filtered time series of the $H, D$ and $Z$ components, respectively, of the magnetic field, in the Pc3 range (three upper panels) and Pc5 range (three lower panels). Right column: panels from top to bottom show the corresponding wavelet power spectra.

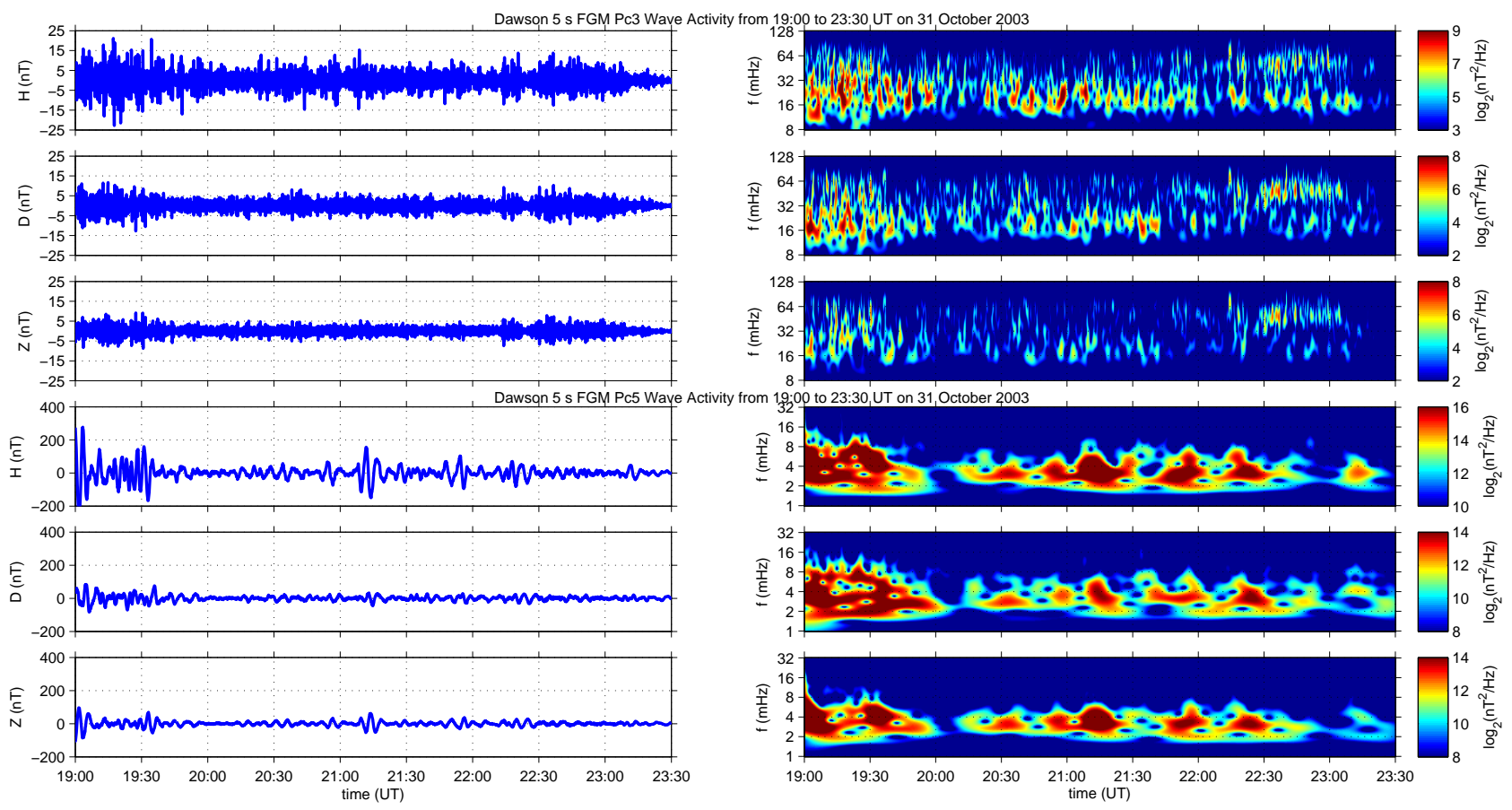

Figure 7. As in Fig. 6 but for the Dawson ground magnetic station. 


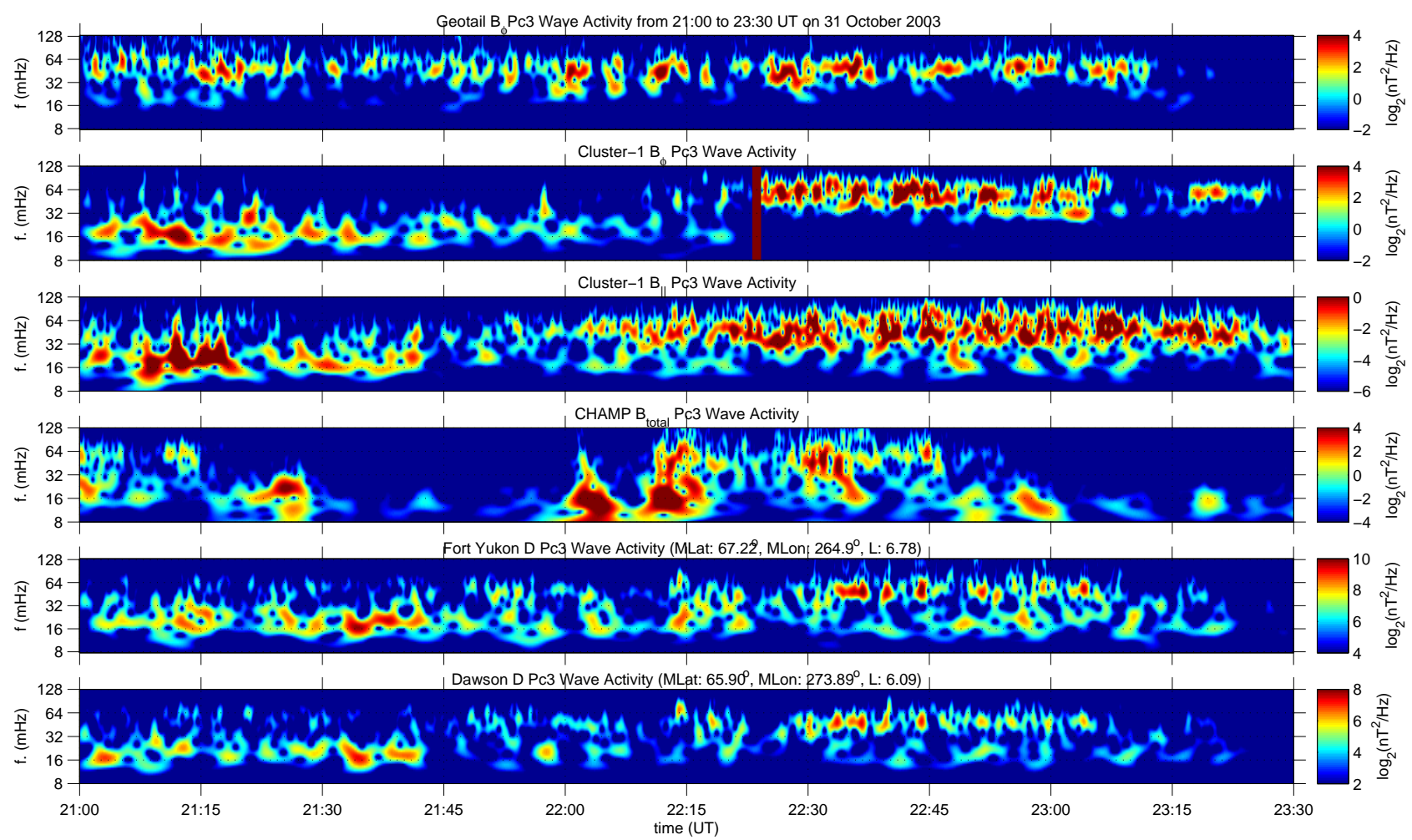

Figure 8. Panels from top to bottom show the wavelet power spectra of the Pc3 wave activity from Geotail toroidal component, Cluster1 toroidal and compressional components, CHAMP total field, and Fort Yukon and Dawson $D$ components from 21:00 to 23:30 UT on 31 October 2003. The time that Cluster enters the plasmasphere boundary layer (PBL) is also marked with a red vertical line in Cluster's toroidal component.

Figure 9 shows a composite of dynamic wavelet power spectra covering the Pc5 frequency band for Geotail (compressional) and Cluster-1 (toroidal and compressional components) as well as observations from GIMA and CARISMA stations ( $D$ components) between 21:00 and 23:30 UT on 31 October 2003. We find that at 22:23 UT, when the higher Pc3 frequency fluctuations appear in the Cluster toroidal mode recordings, the spacecraft entered the plasmasphere boundary layer (PBL; see the red vertical line in Fig. 9), where the plasma ion density was abruptly elevated (see also Zong et al., 2007). This is probably the reason why Pc5 waves are no longer detected by Cluster after 22:23 UT in the toroidal mode, as can be seen in Fig. 9. CHAMP starts to see the higher frequency Pc3 pulsations at 22:11 UT, later than these pulsations were first observed by Cluster, when CHAMP was located at $60.55^{\circ}$ magnetic latitude (MLAT), $265.39^{\circ}$ magnetic longitude (MLON) and $\sim 11: 28 \mathrm{MLT}$, as soon as it entered the dayside auroral oval in the beginning of its descending orbit on the dayside. After 22:47 UT these pulsations disappear from CHAMP as the satellite crosses into the southern hemisphere nightside, while Cluster and the CARISMA station continue recording them. It is evident that these high-frequency Pc3 waves are strictly on the dayside. They are present in the CHAMP data of the previous orbit (in the time interval between 20:30 and 21:30 UT in Fig. 4), but they are not as intense and do not occur in the mid-latitude regions. At 22:13:30 UT, i.e. later than initially observed by CHAMP, the higher-frequency Pc3 pulsations are detected on the ground, at the Fort Yukon and Dawson stations (see Figs. 6, 7 and 8).

These findings are consistent with the hypothesis that the source of the observed dayside Pc3 waves in the magnetosphere are upstream ULF waves generated in the foreshock region. Such waves have a period controlled by the magnitude of the IMF and are believed to enter and propagate through the magnetosphere as compressional waves (e.g. Heilig et al., 2007, and references therein). Furthermore, according to the pressure pulse model (Sibeck, 1990), as dynamic pressure variations in the solar wind batter the magnetopause, large-amplitude boundary waves are driven and fastmode compressional waves are launched into the magnetosphere. The boundary waves are expected to move dawnward across local noon during periods of spiral IMF orientation, similar to the conditions which prevail during the time interval between 19:00 and 23:30 UT on 31 October 2003. Specifically, the IMF longitude varies between 125 and $170^{\circ}$, suggesting that the foreshock lies upstream from the pre-noon 


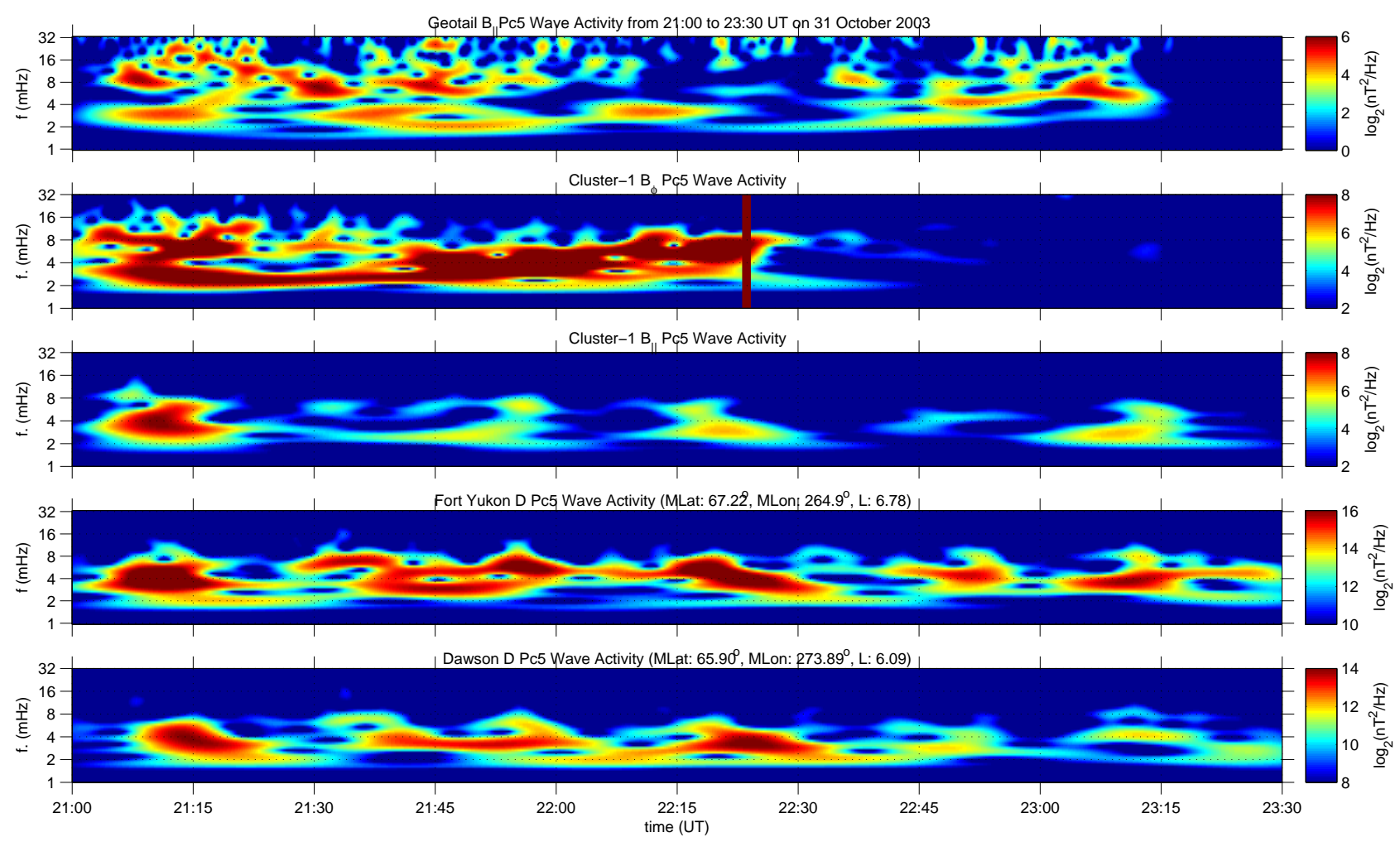

Figure 9. Panels from top to bottom show the wavelet power spectra of the Pc5 wave activity from Geotail compressional component, Cluster-1 toroidal and compressional components, and Fort Yukon and Dawson $D$ components between 21:00 and 23:30 UT on 31 October 2003. The time that Cluster enters the PBL is also marked with a red vertical line in Cluster's toroidal component.

bow shock and the model predicts pre-noon magnetospheric and ionospheric events.

\section{Discussion and conclusions}

The intense solar activity in the end of October 2003 initiated a series of strong magnetospheric disturbances and two successive intense magnetic storms, as two consecutive CMEs impacted the Earth's magnetosphere. The "Halloween" superstorm (29-31 October 2003) has received considerable interest and triggered analysis of both ground and space data, as it offers a great opportunity for understanding the response of the magnetosphere-ionosphere system to strong and continuous solar wind driving. We investigate a specific time interval during the recovery phase of the Halloween storm on 31 October 2003, when the Cluster and CHAMP satellites were in good LT conjunction. We examine separately Pc3 and Pc4-5 ULF wave activity and the wave concurrence in different regions of the magnetosphere, down to the topside ionosphere and on the ground using wavelet transforms.

We used the wavelet transform to examine the spectral properties of ULF waves recorded during the Halloween superstorm at auroral latitudes on the ground, and by spacecraft at low altitudes (CHAMP), near conjunction in the outer magnetosphere (Cluster) and outside the bow shock (Geotail). For the time interval examined, waves were observed at all these dayside locations in both the Pc3 and Pc4-5 bands. The former were likely driven directly by upstream waves originating in the ion foreshock and advected downstream to impact the magnetopause, and the latter by direct solar wind perturbations such as pressure pulses, both occurring mostly on the dayside. The multipoint satellite and ground measurements were able to yield insight into the ULF wave propagation, and we used wavelet analysis to characterise the temporal evolution of ULF spectra at multiple locations in the system under conditions of dynamical excitation.

One of the most striking features of the waves observed was the change in frequency of the waves seen at Cluster from before to after 22:23 UT. Before that time, wave spectra were dominated by Pc4-5 waves; however, after that time there was a sharp change in the spectra where the power in the Pc4-5 band decayed significantly and was replaced by strong Pc3 power with a spectral peak at around 55-60 mHz. In the upstream wave theory, the frequency of the upstream wave generated by the specular reflection of ions is related to the IMF magnitude by $f(\mathrm{mHz})=6 \cdot B_{\mathrm{IMF}}(\mathrm{nT})$ (Yumoto et al., 1984). According to data from the ACE spacecraft orbiting the L1 Lagrange point, as well as Geotail measurements at the dawnside flank of the bow shock, the IMF magnitude 
during this time was around $9 \mathrm{nT}$, in good agreement with the observed $55-60 \mathrm{mHz}$ frequency seen by Cluster in its perigee pass after 22:23 UT.

In Fig. 10 we show the result of a calculation of an estimate of the fundamental mode toroidal field line resonance (FLR) frequency on the L shell of the Cluster satellite between 21:00 and 23:30 UT. We used the analytic formula from the dipole magnetic field model of Allan and Knox (Allan and Knox, 1979; Ozeke and Mann, 2004), which is probably a reasonable approximation for the field geometry at $L \sim 4$ during the Cluster perigee pass at this time. We used the electron density derived from the spacecraft potential, as well as ion density measurements from the Cluster Ion Spectrometry (CIS) experiment instrument (Réme et al., 2001), to estimate the mass density (in Fig. 10 the electron and ion densities variations from the Plasma Electron and Current Experiment (PEACE) instrument onboard Cluster (Johnstone et al., 1997) are also presented for comparison; PEACE data are calibrated via the Waves of High Frequency and Sounder for Probing of Density by Relaxation (WHISPER) instrument onboard Cluster; Décréau et al., 1997). As expected due to spacecraft charging, the electron number density was much larger than the observed total ion number density; however, the CIS instrument indicated a significant population of $\mathrm{O}^{+}$ ions at this time (still much smaller than the electron density by number). To make analytic progress, but take into account the presence of the heavy ions, we included the mass density component by number as observed for $\mathrm{O}^{+}$, as well as $\mathrm{He}^{+}$and $\mathrm{He}^{++}$, assuming the remaining ion population was made up of protons to match quasi-neutrality with the electron number density. During this time the Cluster satellites also crossed close to the equator, such that the mass density can be assumed to be a good approximation to that at the equatorial plane - an assumption consistent with the results of Goldstein et al. (2001), who showed using Polar data that there is in general only a weak dependence of electron density along the field line close to the equatorial plane. Finally, the magnetic field strength observed by Cluster was mapped from the observed dipole magnetic latitude to the dipole equator using a dipole model and combined with the derived mass density to provide a proxy for the equatorial Alfvén speed required to compute the FLR frequency in the Allan and Knox model.

Interestingly, Fig. 10 shows that before 22:23 UT the model toroidal FLR eigenfrequency derived from the Cluster observations was in the Pc4-5 range and increased with time. This is consistent with the expectation that driving fast-mode waves in the Pc4-5 (1-22 mHz) band would be absorbed at a higher L shells, before 22:23 UT on Cluster, and be unable to penetrate past the turning point to lower L shells at later times. In contrast, the model predicts a toroidal FLR frequency of $\sim 60 \mathrm{mHz}$ at later times on the $\mathrm{L}$ shells close to perigee. This is consistent with higher-frequency fast-mode waves being able to resonate with local Alfvén waves at these lower L shells consistent with the Cluster observations. The fact that the observed Pc3 frequency fits with that expected from upstream waves whose frequency is controlled by the IMF magnitude further supports the hypothesis that this was the source of the burst of observed $\sim 50 \mathrm{mHz}$ Pc3 waves.

One thing which is not well understood is why the Pc3 waves at around $55-60 \mathrm{mHz}$ turn on abruptly around 22:00 UT as seen in the ground magnetometer data, being seen shortly thereafter on the Cluster satellites as Cluster 1 reaches the $\mathrm{L}$ shells whose resonance frequency matches the expected frequency of the driving upstream waves. We examined the ACE data (Fig. 11) but could not find strong evidence of any clear rotation from large to small solar wind cone angles. (ACE gives, for the time interval examined, solar wind cone angles between 30 and $40^{\circ}$.) Such rotations are believed to be associated with the quasi-parallel shock moving towards the sub-solar point, such that the downstream stream lines would then impact the near-noon magnetopause, enabling the upstream waves to drive Pc3 wave power into the magnetosphere (e.g. Greenstadt and Olson, 1976). At this time, ACE is located at $\operatorname{GSM}(232,37.7,-25.7) R_{\mathrm{E}}$ such that its location places it around 45.6 $R_{\mathrm{E}}$ from the Sun-Earth line. Consequently, it is possible that the magnetic field in the solar wind which impacted the Earth is not well represented in the ACE magnetic field data. King and Papitashvili (2005) have shown statistically that IMF variations in the solar wind are typically small on scale sizes $\sim<50$ Re. However, during this very active time it is possible that there were angle changes which were not captured by ACE, especially considering that these waves were observed during the dynamic Halloween superstorm interval.

Fortunately, for the time interval examined, Geotail was exposed to the IMF, which was located outside the bow shock at the dawn flank. Figure 11 shows the cone angle as measured by Geotail, for the time interval from 19:30 to 23:59 UT, from which it can be seen that it is possible that there was a cone angle rotation upstream of the Earth, since the cone angle changes from values of $\sim 55^{\circ}$ at $\sim 19: 45 \mathrm{UT}$ to $\sim 15-40^{\circ}$. This coincides with the Geotail spectra, and especially the azimuthal component, from which it can be seen that there is an enhancement of high-frequency wave activity after 21:00 UT. As discussed by Greenstadt and Olson (1976), there can be a prevalence of Pc3 waves for cone angles $<50-60^{\circ}$, suggesting a possible link to an upstream wave source for the waves seen both by Cluster and on the ground, although as noted by these authors there can be significant variability.

Turning to the data from low Earth orbit, CHAMP recorded the high-frequency band of Pc3 waves only over the northern dayside auroral zone and dayside equatorial zone. Following the intensification of the high-frequency band after 22:00 UT visible in the Geotail observations, CHAMP recorded the waves throughout its entire orbit on the dayside, and not solely over the auroral and equatorial zones as is the case during quieter periods. This happened presumably because, after 22:00 UT, Pc3 waves were driven from 

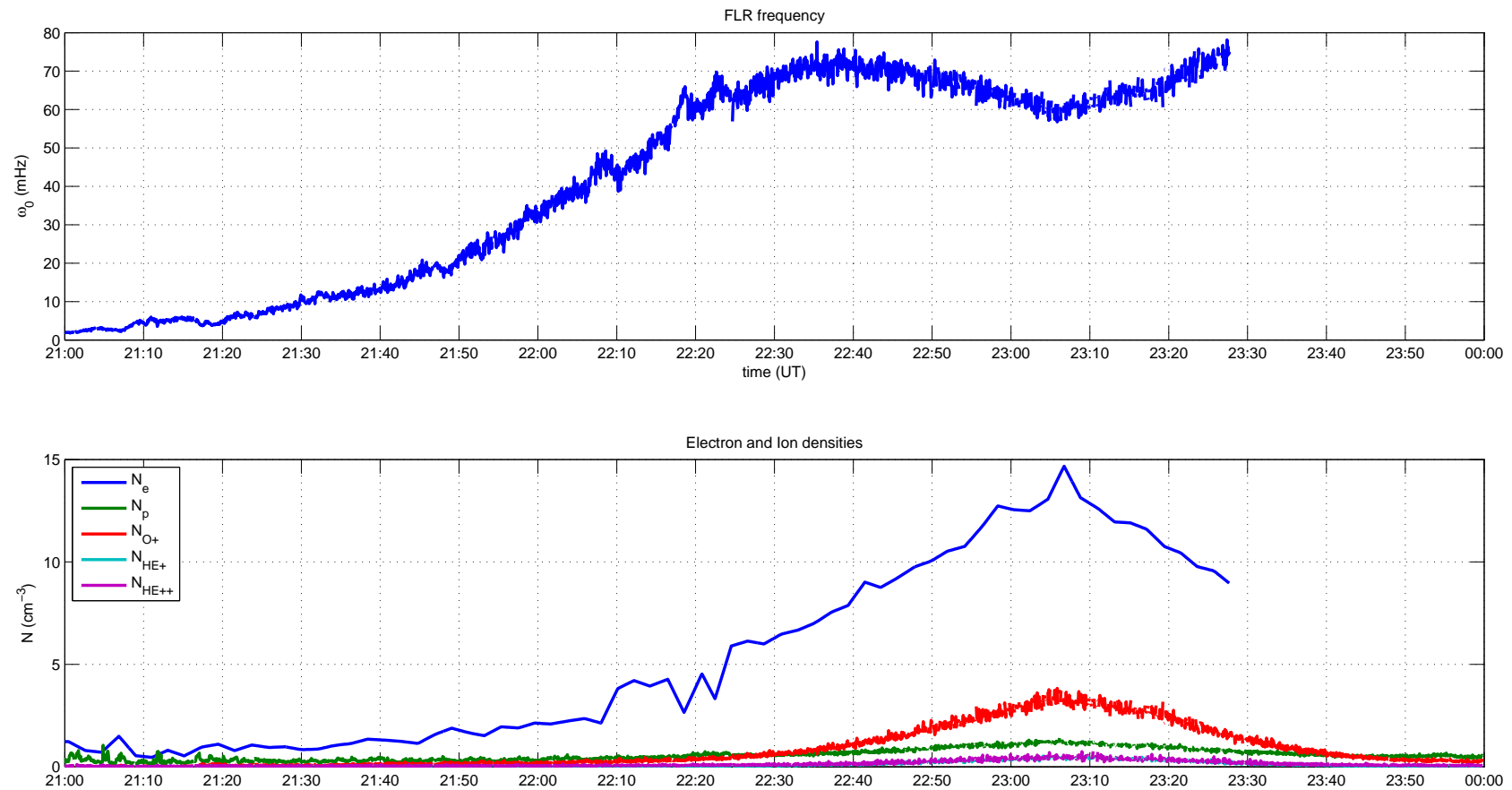

Figure 10. The toroidal FLR eigenfrequency $\omega_{0}$ derived from the Cluster observations (top panel). The calculation of the FLR profile was based upon Eq. (16) provided by Ozeke and Mann (2004). In Eq. (16) $A_{0}$ depends upon magnetic field magnitude and mass density. Additionally, the electron and ion densities variations from the PEACE and CIS instruments onboard Cluster are also presented (bottom panel).
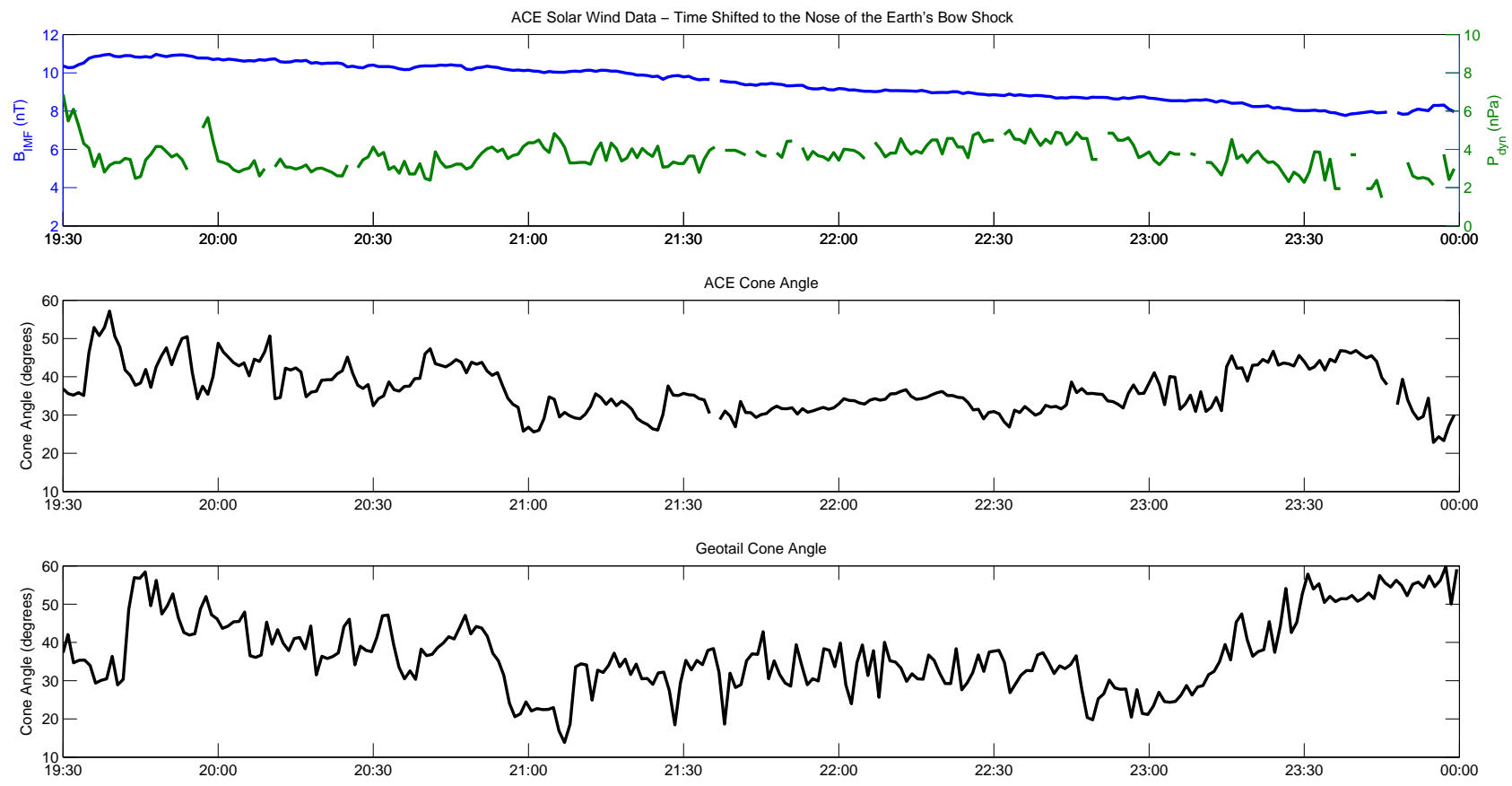

Figure 11. ACE solar wind data $\left(B_{\mathrm{IMF}}\right.$ and $\left.P_{\mathrm{dyn}}\right)($ top panel) and IMF cone angles from 19:30 to 23:59 UT on 31 October 2003 for ACE (middle panel) and Geotail (bottom panel).

the injection of waves from the upstream wave source at the bow shock, being both stronger and ducted to all dayside lat- itudes after this time. A point that still needs to be clarified is the strong north-south asymmetry in the Pc3 wave obser- 


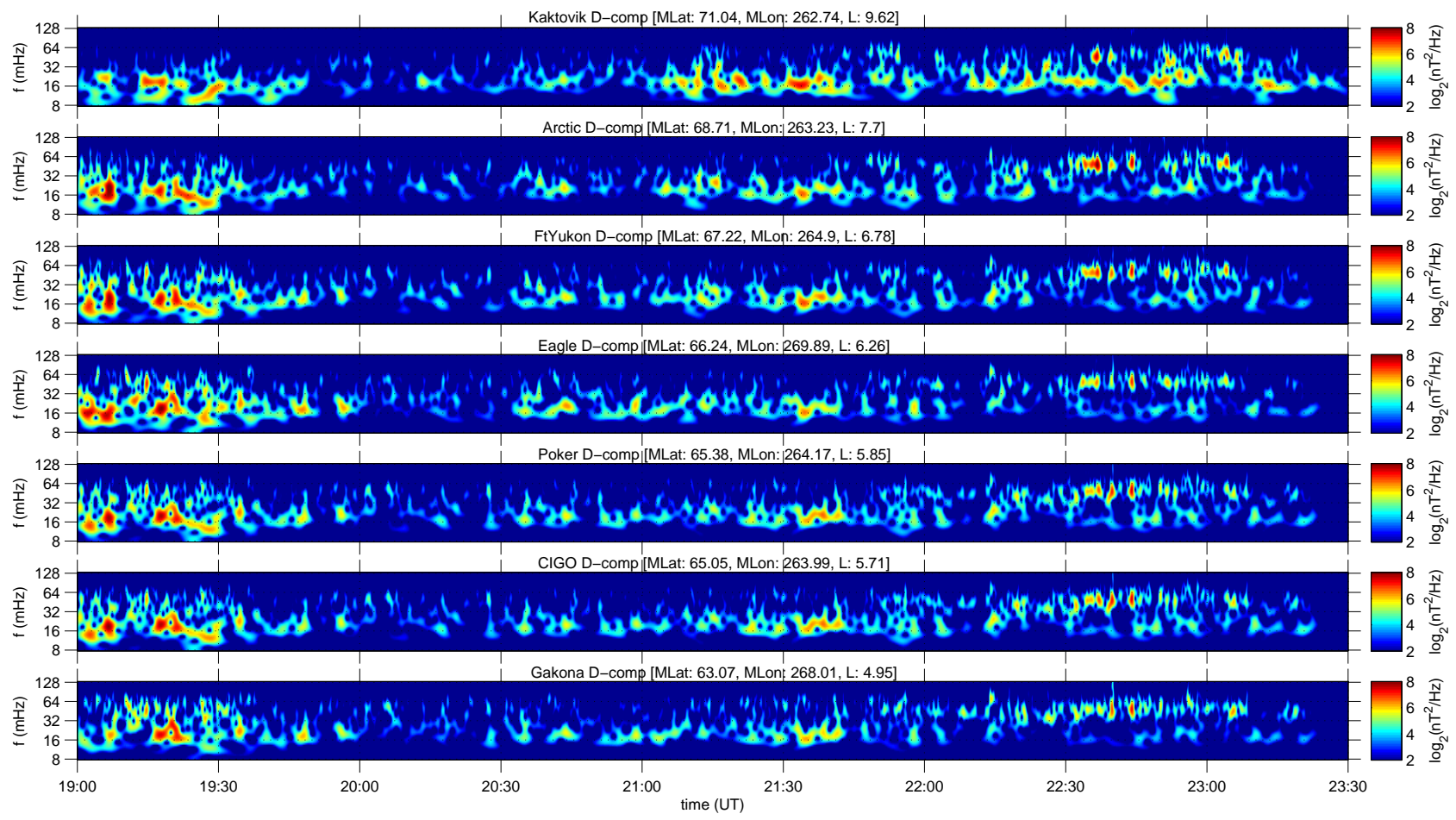

Figure 12. Panels from top to bottom are shown the wavelet power spectra in the Pc3 range of the $D$ components of the GIMA ground magnetometer array stations from 19:00 to 23:30 UT on 31 October 2003.

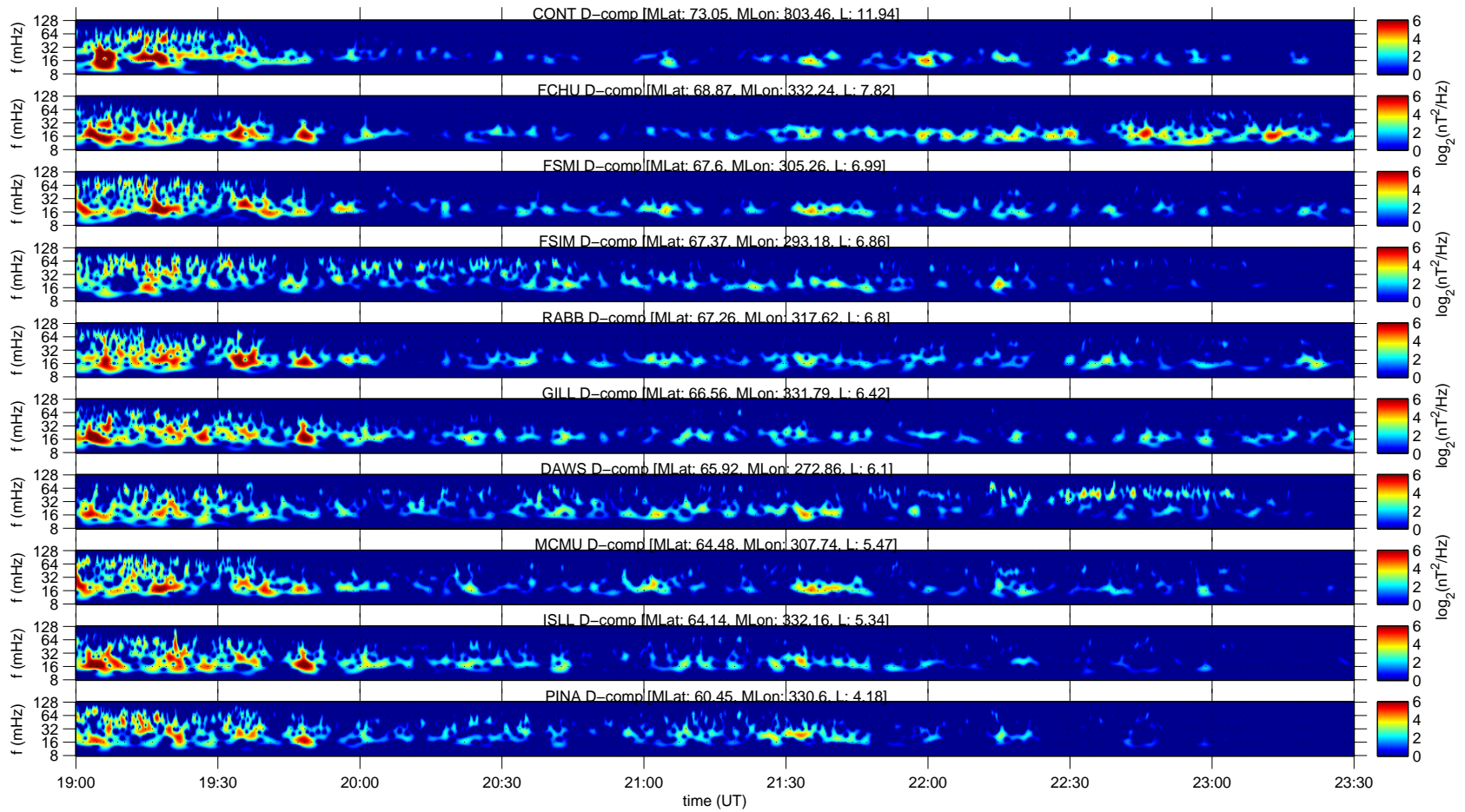

Figure 13. As in Fig. 12 but for the CARISMA network. 
vations. In the topside ionosphere, the waves are developed only where conductivity is increased: on the dayside and at equatorial and auroral regions of strong currents. Nonetheless, when their intensity has become significantly strong, waves can be seen at sub-auroral and mid-latitudes, but even then still only on the illuminated dayside.

The Alaska magnetometer stations (GIMA network), which were located on the dayside and close to the Cluster footprint during the time interval investigated, all recorded the onset of the strong high-frequency band after 22:00 UT (Fig. 12), i.e. after it was detected by Geotail and Cluster (see Fig. 8). The same Pc3 waves and intensification is seen in the observations of Dawson - the westernmost station of CARISMA. Interestingly enough, magnetic stations along the Churchill line in the CARISMA array, which are located further east at approximately 14:00-15:00 MLT, did not observe clear waves in the afternoon local times sector (Fig. 13). This lead us to the conclusion that this highfrequency band is most easily seen close to local noon, directly driven by bow shock upstream wave disturbances which are attached to streamlines which impact the magnetopause and hence drive waves in the near-noon and dayside magnetosphere and which can propagate to mid-latitudes with $L \sim 4$ (see, for example, Russell et al., 1983).

An important issue for ULF wave observations with LEO satellites is the Doppler shift of waves due to the rapid motion of the satellite. For instance, Le et al. (2011) reported on a unique type of ULF wave observed by ST5, in the Pc23 frequency range. The coordinated ground-based magnetic observations at the spacecraft footprints, however, did not record waves in the Pc2-3 band; instead, the waves appear to be the common Pc4-5 waves associated with field line resonances. Le et al. (2011) suggested that these unique Pc23 waves seen by ST5 are in fact the Doppler-shifted Pc4-5 waves as a result of rapid traverse of the spacecraft across the resonant field lines azimuthally at low altitudes. In another study Balasis et al. (2012) showed that the simultaneous activation of pulsations in the Pc3 and Pc5 frequency ranges in the magnetosphere is possible. If the amplitudes of $\mathrm{Pc} 3$ waves in the $\mathrm{F}$ layer are within several tenths of a nanotesla and their wavelengths $k \geq 10^{-2} \mathrm{~km}^{-1}$, only Pc3 waves would be recorded by an ionospheric satellite due to its high speed, and only Pc5 waves would be seen on the ground surface because of the effective ionospheric attenuation of Pc3 activity (Yagova et al., 2015). This means that synchronous recording of ground Pc5 pulsations and ionospheric Pc3 waves does not necessarily indicate that the ionospheric signal is a Doppler-shifted Pc4-5. Thus, further case studies of Pc3 wave events recorded simultaneously in several locations of the geospace are necessary and a new multi-satellite LEO mission like the ESA's recently launched Swarm mission is expected to help with resolving this issue.

Moreover, Yagova et al. (2015) observed ground-toionosphere ULF wave amplitude ratios between MM100 ground magnetometer network stations and the CHAMP satellite, corresponding to a Doppler shift $\Delta f=6.4 \mathrm{mHz}$ (i.e. within a few percent of the apparent frequency of the Pc2-3 pulsations recorded by a low-orbiting spacecraft). These calculations could also apply to the case study presented in this paper.

A better understanding of the wave propagation mechanism throughout the magnetosphere, and down to the topside ionosphere and even to the Earth's surface, can help ULF wave diagnostic studies to reach their full potential. As our results demonstrate, combined interpretation of magnetic field data from the magnetosphere, topside ionosphere and ground can lead to substantial advances in the understanding of ULF wave occurrence, propagation, and development. Topside ionosphere studies can now utilise multisatellite missions like Swarm, whilst the magnetosphere is becoming ever more populated with spacecraft such as ESA's Cluster and NASA's THEMIS and Van Allen Probes. Together with supporting ground-based magnetometer arrays, such infrastructure can provide exceptional multipoint data sets with which to reveal the nature, role and impacts of ULF waves for energy transport in the inhomogeneous and coupled geospace system.

Acknowledgements. This research was co-financed by the European Union (European Social Fund, ESF) and Greek national funds through the Operational Programme "Education and Lifelong Learning" of the National Strategic Reference Framework (NSRF) - Research Funding Programme: "Thales. Investing in knowledge society through the European Social Fund". This work received funding from the European Space Agency under contracts ESTEC 4000103770/11/NL/JA/ef and 4000114090/15/NL/MP. We gratefully acknowledge ESA's Cluster Active Archive; Helmholtz Centre Potsdam GFZ (German Research Centre for Geosciences); DARTS at the Institute of Space and Astronautical Science; JAXA in Japan; the Canadian Space Agency; and the Geophysical Institute, University of Alaska Fairbanks, for providing the data used in this study. CARISMA is operated by the University of Alberta, funded by the Canadian Space Agency. I. R. Mann is supported by a Discovery Grant from the Canadian NSERC.

The topical editor C.-P. Escoubet thanks P. M. E. Decreau and one anonymous referee for help in evaluating this paper.

\section{References}

Allan, W. and Knox, F. B.: A dipole field model for axisymmetric Alfvén waves with finite ionosphere conductivities, Planet. Space Sci., 27, 79-85, 1979.

Anderson, B. J., Erlandson, R. E., and Zanetti, L. J.: A statistical study of Pc 1-2 magnetic pulsations in the equatorial magnetosphere: 2. Wave properties, J. Geophys. Res., 97, 3089-3101, 1992.

Baker, D. N. and Daglis, I. A.: Radiation belts and ring current, in: Space Weather - Physics and Effects, edited by: Bothmer, V. and Daglis, I. A., Springer Verlag, Berlin, Germany, 173-202, 2007.

Balasis, G., Maus, S., Lühr, H., and Rother, M.: Wavelet analysis of CHAMP flux gate magnetometer data, in: Earth Observation 
with CHAMP, edited by: Reigber, C., Lühr, H., Schwintzer, P., and Wickert, J., Springer, New York, USA, 347-352, 2005.

Balasis, G., Daglis, I. A., Zesta, E., Papadimitriou, C., Georgiou, M., Haagmans, R., and Tsinganos, K.: ULF wave activity during the 2003 Halloween superstorm: multipoint observations from CHAMP, Cluster and Geotail missions, Ann. Geophys., 30, 1751-1768, doi:10.5194/angeo-30-1751-2012, 2012.

Balasis, G., Daglis, I. A., Georgiou, M., Papadimitriou, C., and Haagmans, R.: Magnetospheric ULF wave studies in the frame of Swarm mission: a time-frequency analysis tool for automated detection of pulsations in magnetic and electric field observations, Earth Planets Space, 65, 1385-1398, 2013.

Bortnik, J., Cutler, J. W., Dunson, C., and Bleier, T. E.: An automatic wave detection algorithm applied to Pc1 pulsations, J. Geophys. Res., 112, A04204, doi:10.1029/2006JA011900, 2007.

Boudouridis, A. and Zesta, E.: Comparison of Fourier and wavelet techniques in the determination of geomagnetic field line resonances, J. Geophys. Res., 112, A08205, doi:10.1029/2006JA011922, 2007.

Chi, P. J. and Russell, C. T.: Use of the Winger-Ville distribution in interpreting and indentifying ULF waves in triaxial magnetic records, J. Geophys. Res., 113, A01218, doi:10.1029/2007JA012469, 2008.

Décréau, P. M. E., Fergeau, P., Krannosels'kikh, V., Lévêque, M., Martin, Ph., Randriamboarison, O., Sené, F. X., Trotignon, J. G., Canu, P., and Mögensen, P. B.: Whisper, a resonance sounder and wave analyser: performances and perspectives for the Cluster mission, Space Sci. Rev., 79, 93-105, 1997.

Engebretson, M. J., Posch, J. L., Westerman, A. M., Otto, N. J., Slavin, J. A., Le, G., Strangeway, R. J., and Lessard, M. R.: Temporal and spatial characteristics of Pc1 waves observed by ST5, J. Geophys. Res., 113, A07206, doi:10.1029/2008JA013145, 2008.

Fairfield, D. H.: Average and unusual locations of the Earth's magnetopause and bow shock, J. Geophys. Res., 76, 6700-6716, 1971.

Goldstein, J., Denton, R. E., Hudson, M. K., Miftakhova, E. G., Young, S. L., Menietti, J. D., and Gallagher, D. L.: Latitudinal density dependence of magnetic field lines inferred from Polar plasma wave data, J. Geophys. Res., 106, 6195-6201, doi:10.1029/2000JA000068, 2001

Greenstadt, E. W. and Olson, J. V.: Pc 3, 4 activity and interplanetary field orientation, J. Geophys. Res., 81, 5911-5920, doi:10.1029/JA081i034p05911, 1976.

Heilig, B., Lühr, H., and Rother, M.: Comprehensive study of ULF upstream waves observed in the topside ionosphere by CHAMP and on the ground, Ann. Geophys., 25, 737-754, doi:10.5194/angeo-25-737-2007, 2007.

Horne, R., Thorne, R. M., Shprits, Y. Y., Meredith, N. P., Glauert, S. A., Smith, A. J., Kanekal, S. G., Baker, D. N., Engebretson, M. J., Posch, J. L., Spasojevic, M., Inan, U. S., Pickett, J. S., and Decreau, P. M. E.: Wave acceleration of electrons in the van Allen radiation belts, Nature, 437, 7227-7230, doi:7010.1038/nature03939, 2005.

Jacobs, J. A., Kato, Y., Matsushita, S., and Troitskaya, V. A.: Classification of geomagnetic micropulsations, J. Geophys. Res., 69, 180-181, 1964.

Jadhav, G., Rajaram, M., and Rajaram, R.: Modification of daytime compressional waves by the ionosphere: first results from Oersted, Geophys. Res. Lett., 28, 103-106, 2001.
Johnstone, A. D., Alsop, C., Burge, S., Carter, P. J., Coates, A. J., Coker, A. J., Fazakerley, A. N., Grande, M., Gowen, R. A., Gurgiolo, C., Hancock, B. K., Narheim, B., Preece, A., Sheather, P. H.,, Winningham, and Woodliffe, R. D.: PEACE: A plasma electron and current experiment, Space Sci. Rev., 79, 351-398, 1997.

Kataoka, R., Miyoshi, Y., and Morioka, A.: Hilbert-Huang Transform of geomagnetic pulsations at auroral expansion onset, $\mathrm{J}$ Geophys. Res., 114, A09202, doi:10.1029/2009JA014214, 2009.

King, J. H. and Papitashvili, N. E.: Solar wind spatial scales in and comparisons of hourly Wind and ACE plasma and magnetic field data, J. Geophys. Res., 110, A02104, doi:10.1029/2004JA010649, 2005.

Le, G., Chi, P. J., Strangeway, R. J., and Slavin, J. A.: Observations of a unique type of ULF wave by low altitude Space Technology 5 satellites, J. Geophys. Res., 116, A0820, doi:10.1029/2011JA016574, 2011.

Liu, W., Sarris, T. E., Li, X., Ergun, R., Angelopoulos, V., Bonnell, J., and Glassmeier, K.-H.: Solar wind influence on Pc4 and Pc5 ULF wave activity in the inner magnetosphere, J. Geophys. Res., 115, A12201, doi:10.1029/2010JA015299, 2010.

Loto'aniu, T. M., Mann, I. R., Ozeke, L. G., Chan, A. A., Dent, Z. C., and Milling, D. K.: Radial diffusion of relativistic electrons into the radiation belt slot region during the 2003 Halloween geomagnetic storms, Geophys. Res., 111, A04218, doi:10.1029/2005JA011355, 2006.

Menk, F.: Magnetospheric ULF Waves: A Review, in: The Dynamic Magnetosphere, edited by: Liu, W. and Fujimoto, M., IAGA Special Sopron Book Series, Springer, the Netherlands, 3, 223-256, 2011.

Murphy, K. R., Rae, I. J., Mann, I. R., Milling, D. K., Watt, C. E. J., Ozeke, L., Frey, H. U., Angelopoulos, V., and Russell, C. T.: Wavelet-based ULF wave diagnosis of substorm expansion phase onset, J. Geophys. Res., 114, A00C16, doi:10.1029/2008JA013548, 2009.

Ndiitwani, D. C. and Sutcliffe, P. R.: The structure of lowlatitude Pc3 pulsations observed by CHAMP and on the ground, Ann. Geophys., 27, 1267-1277, doi:10.5194/angeo-27-12672009, 2009.

Ozeke, L. G. and Mann, I. R.: Modeling the properties of guided poloidal Alfvén waves with finite asymmetric ionospheric conductivities in a dipole field, J. Geophys. Res., 109, A05205, doi:10.1029/2003JA010151, 2004.

Pilipenko, V., Fedorov, E., Heilig, B., Engebretson, M. J., Sutcliffe, P., and Lühr, H.: ULF Waves in the Topside Ionosphere: Satellite Observations and Modeling, in: The Dynamic Magnetosphere, edited by: Liu, W. and Fujimoto, M., IAGA Special Sopron Book Series, Springer, the Netherlands, 3, 257-269, 2011.

Rème, H., Aoustin, C., Bosqued, J. M., Dandouras, I., Lavraud, B., Sauvaud, J. A., Barthe, A., Bouyssou, J., Camus, Th., Coeur-Joly, O., Cros, A., Cuvilo, J., Ducay, F., Garbarowitz, Y., Medale, J. L., Penou, E., Perrier, H., Romefort, D., Rouzaud, J., Vallat, C., Alcaydé, D., Jacquey, C., Mazelle, C., d’Uston, C., Möbius, E., Kistler, L. M., Crocker, K., Granoff, M., Mouikis, C., Popecki, M., Vosbury, M., Klecker, B., Hovestadt, D., Kucharek, H., Kuenneth, E., Paschmann, G., Scholer, M., Sckopke, N., Seidenschwang, E., Carlson, C. W., Curtis, D. W., Ingraham, C., Lin, R. P., McFadden, J. P., Parks, G. K., Phan, T., Formisano, V., Amata, E., Bavassano-Cattaneo, M. B., Baldetti, P., Bruno, R., Chionchio, G., Di Lellis, A., Marcucci, M. F., Pallocchia, G., Korth, 
A., Daly, P. W., Graeve, B., Rosenbauer, H., Vasyliunas, V., McCarthy, M., Wilber, M., Eliasson, L., Lundin, R., Olsen, S., Shelley, E. G., Fuselier, S., Ghielmetti, A. G., Lennartsson, W., Escoubet, C. P., Balsiger, H., Friedel, R., Cao, J.-B., Kovrazhkin, R. A., Papamastorakis, I., Pellat, R., Scudder, J., and Sonnerup, B.: First multispacecraft ion measurements in and near the Earth's magnetosphere with the identical Cluster ion spectrometry (CIS) experiment, Ann. Geophys., 19, 1303-1354, doi:10.5194/angeo19-1303-2001, 2001.

Russell, C. T., Luhmann, J. G., Odera, T. J., and Stuart, W. F.: The rate of occurrence of dayside Pc 3, 4 pulsations: The L-value dependence of the IMF cone angle effect, Geophys. Res. Lett., 10, 663-666, 1983.

Sarris, T. E., Liu, W., Li, X., Kabin, K., Talaat, E. R., Rankin, R., Angelopoulos, V., Bonnell, J., and Glassmeier, K.-H.: THEMIS observations of the spatial extent and pressure-pulse excitation of field line resonances, Geophys. Res. Lett., 37, L15104, doi:10.1029/2010GL044125, 2010.

Sarris, T. E.: Estimates of the power per mode number of broadband ULF waves at geosynchronous orbit, J. Geophys. Res., 119, 5539-5550, doi:10.1002/2013JA019238, 2014.

Sibeck, D. G.: A model for the transient magnetospheric response to sudden solar wind dynamic pressure variations, J. Geophys. Res., 95, 3755-3771, doi:10.1029/JA095iA04p03755, 1990.

Sibeck, D. G., Lopez, R. E., and Roelof, E. C.: Solar wind control of the magnetopause shape, location, and motion, J. Geophys. Res., 96, 5489-5495, 1991.

Southwood, D. J. and Kivelson, M. G.: The magnetohydrodynamic response of the magnetospheric cavity to changes in solar wind pressure, J. Geophys. Res., 95, 2301-2309, doi:10.1029/JA095iA03p02301, 1990.

Stolle, C., Lühr, H., Rother, M., and Balasis, G.: Magnetic signatures of equatorial spread $\mathrm{F}$ as observed by the CHAMP satellite, J. Geophys. Res., 111, A02304, doi:10.1029/2005JA011184, 2006.
Sutcliffe, P. R. and Lühr, H.: A comparison of Pi2 pulsations observed by CHAMP in low Earth orbit and on the ground at low latitudes, Geophys. Res. Lett., 30, 2105, doi:10.1029/2003GL018270, 2003.

Takahashi, K. and Anderson, B.: Distribution of ULF Energy $(f<$ $80 \mathrm{mHz}$ ) in the Inner Magnetosphere: A Statistical Analysis of AMPTE CCE Magnetic Field Data, J. Geophys. Res., 97, 1075110773, 1992.

Vellante, M., Lühr, H., Zhang, T. L., Wesztergom, V., Villante, U., De Lauretis, M., Piancatelli, A., Rother, M., Schwingenschuh, K., Koren, W., and Magnes, W.: Ground/satellite signatures of field line resonance: A test of theoretical predictions, J. Geophys. Res., 109, A06210, doi:10.1029/2004JA010392, 2004.

Wang, H., Lühr, H., Ma, S. Y., Weygand, J., Skoug, R. M., and Yin, F.: Field-aligned currents observed by CHAMP during the intense 2003 geomagnetic storm events, Ann. Geophys., 24, 311324, doi:10.5194/angeo-24-311-2006, 2006.

Yagova, N., Heilig, B., and Fedorov, E.: Pc2-3 geomagnetic pulsations on the ground, in the ionosphere, and in the magnetosphere: MM100, CHAMP, and THEMIS observations, Ann. Geophys., 33, 117-128, doi:10.5194/angeo-33-117-2015, 2015.

Yumoto, K., Saito, T., Tsurutani, B. T., Smith, E. J., and Akasofu, S.-I.: Relationship between the IMF magnitude and Pc 3 magnetic pulsations in the magnetosphere, J. Geophys. Res., 89, 9731-9740, 1984.

Zong, Q.-G., Zhou, X.-Z., Li, X., Song, P., Fu, S. Y., Baker, D. N., Pu, Z. Y., Fritz, T. A., Daly, P., Balogh, A., and Reme, H.: Ultra-low frequency modulation of energetic particles in the dayside magnetosphere, Geophys. Res. Lett., 34, L12105, doi:10.1029/2007GL029915, 2007. 